\title{
Initial Analysis of Water Budget in Koshi Basin, Nepal: Assumptions and limitations
}

\author{
D.J. Penton $^{\text {a }}$, L.E. Neumann ${ }^{\text {a }}$, M. Dolk ${ }^{\text {b }}$, H. Zheng ${ }^{\text {a }}$ \\ ${ }^{a}$ CSIRO Land and Water, Australia, ${ }^{b}$ University of Oxford, United Kingdom \\ Email: dave.penton@,csiro.au
}

\begin{abstract}
A growing number of studies use hydrological and cryospheric models to understand the water budget of the Himalayan basins of Nepal. These studies are important because they inform strategic basin development and investment in infrastructure; e.g. the proposed storage-based hydropower schemes for the Dudh Koshi River, currently under assessment by the Asian Development Bank. For large infrastructure schemes, understanding the development options requires hydrological models to explain how one proposed scheme may affect others, and the cumulated impacts of proposed schemes on downstream riparian water access and ecological function. These models also need to provide insights on the resilience of the system to the changing climate, and the climate's effect on water stored in glaciers.

This paper provides an initial water budget of the Koshi Basin region. It discusses the assumptions that are made, and how estimated water availability under climate change is sensitive to these assumptions. The contribution of this paper is to highlight known model limitations and provide a reasonable synthesis of available hydrological information.

The method for undertaking the analysis includes: modelling of rainfall and snow extents; developing a hydrologic model with snow and glacier components; regional calibration of snow parameters, and local calibration of hydrological parameters; and sensitivity analysis of selected parameters. We estimated daily rainfall at locations below 3000mASL using observations from 288 rainfall stations. Independent crossvalidation showed average of $20 \%$ bias, which was sufficient for the regional scale analysis. However, the lack of data at higher elevations allowed erroneous trends to emerge, so we relied on global reanalysis datasets above $3000 \mathrm{mASL}$ ( 0.5 degree grid) because the outputs were constrained by the modelled physics. Despite being better, the global datasets have limitations of resolution and accuracy. MODIS snow cover products allowed the snow processes to be constrained in the hydrological modelling, but they suffered from cloud cover issues. These were partially addressed through the use of Hidden Markov Model approaches to filter noise and provide a daily time-series of snow extent.
\end{abstract}

A GR4J model with additional snow and glacier melt model (GR4JSG) was applied to six alpine catchments (Nepal et al, 2017). The model was able to reflect stream-flow (median 10\% bias) and snow-extent characteristics (median 18\% bias). Some parameter values did not make conceptual sense for the catchment (low degree day factors, large conceptual soil storage $\sim \mathrm{x}_{1}$, large groundwater exchange term $\sim \mathrm{x}_{2}$ ) and probably represent poor input data. For the Tibetan Plateau, many assumptions were required about the correct model structure and parameterisation given poor input climate records and no streamflow measurements on the Plateau itself.

Our initial analysis is strongly affected by assumptions of glacial change. This study estimated that snow contributes around 7\% (3500 MCM) of the annual streamflow of the Koshi River as it exits Nepal at the border and ice melt contributes a further 3\% (1500 MCM). The major carriers of water are the Arun (33\%) and Sun Koshi Rivers (49\%). Runoff is being generated predominantly at elevations between 2000mASL and $4000 \mathrm{mASL}$ - around the same elevation as snow fall is greatest. The greatest uncertainty remains the rainfall at high elevations and the appropriate parameterisation and conceptualisation of snow and glacier models.

Keywords: Himalayan water budget, cryosphere, Koshi Basin 


\section{INTRODUCTION}

The Government of Nepal is encouraging expansion of the hydropower sector to support domestic energy needs and promote economic growth (e.g. $10,000 \mathrm{MW}$ in 10 years from a base of circa $700 \mathrm{MW}$ ). The sustainable development of the hydropower sector requires understanding the system-wide cumulative impacts of development on other hydropower projects, potential irrigation diversions and ecological function. Sustainable development also requires anticipating how projected changes in climate will affect the sharing of benefits from the water resource.

Water resource planners use hydrological models to understand the current water resource availability, including when water is available through the year. Because of the region's characteristics, the models must account for the effect of both rainfall and cryospheric processes. In the Eastern Himalayas, runoff is dominated by rainfall, which falls mostly in the monsoon period (Jun-Sep). Runoff is also driven by temperature which melts snow and glaciers. For these purposes, scientists have applied a range of conceptual or distributed hydrological models in the region including J2000 (Nepal et al, 2015), SRM (Panday et al, 2014), SPHY (Lutz et al, 2014), SWAT (Bharati et al, 2012) and GR4JSG (Nepal et al, 2017).

In this study, we use GR4JSG to understand the water budget of the Koshi Basin, a headwater of the Ganges, in Eastern Nepal. We chose this model, an extension to the GR4J hydrological model (Perrin et al. 2003), because it has modest requirements for inputs, few parameters and its performance enables the exploration of many parameterisations. The catchment contains Himalayan peaks including Mount Everest, the fertile middle mountains (known as the Mahabharat range), and the cold and desolate Tibetan Plateau to the North. In the middle mountains, e.g. at Taplejung station in Tamor catchment, it receives $2 \mathrm{~m}$ annual rainfall with about $74 \%$ of during the summer monsoon (Nepal, 2012). The average maximum temperature is $29^{\circ} \mathrm{C}$ in July and $19^{\circ} \mathrm{C}$ in January (MFD, 2016). According to historic climate records, the temperature is warming around $0.045^{\circ} \mathrm{C} /$ year and according to median of 42 CMIP5 projections for RCP8.5 it will continue to warm at the same or greater rate (Penton et al, 2016). There is no significant trend in rainfall observed in the historic record for the catchment. At some streamflow sites there is a decreasing annual flow rate (e.g. Tamor).

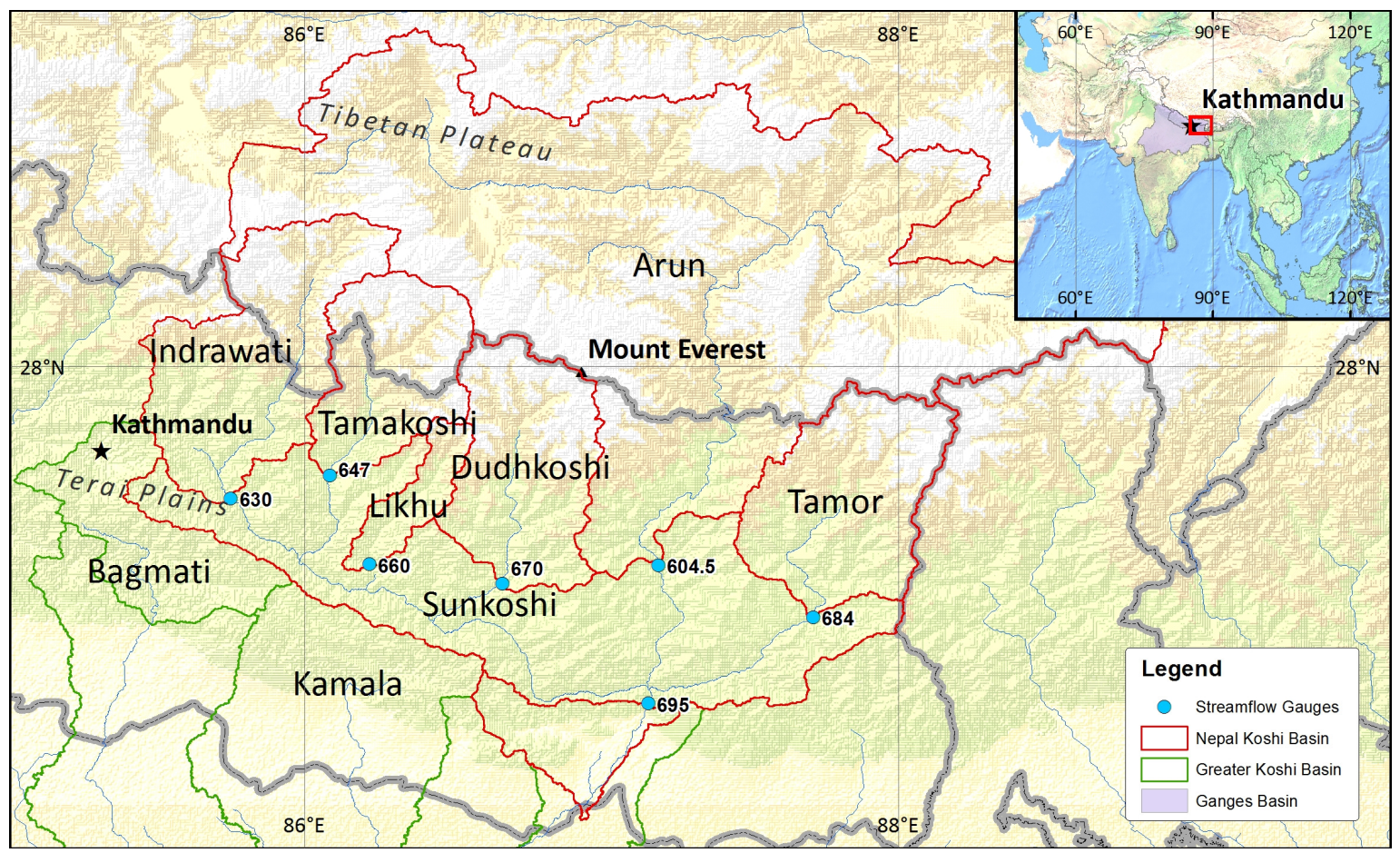

Figure 1. The Koshi Basin in Nepal including catchments: Arun, Indrawati, Tamakoshi, Likhu, Dudhkoshi, Tamor and Sunkoshi

\section{METHODS}

We used the GR4JSG hydrological model to attribute and reconcile terms of the water budget including snow and glacier runoff (with the $\mathrm{T}_{\text {fraction }}$ raito for air/soil temperature differences described in Penton et al, 2017). The model is a conceptual rainfall runoff model, based on GR4J, with water stores for production (of size $\mathrm{x}_{1} \mathrm{~mm}$ ), routing (of size $\mathrm{x}_{3} \mathrm{~mm}$ ), snow and ice, as shown in Figure 2. Features of GR4J include: unit hydrographs to 
control timing of runoff ( $\mathrm{x}_{4}$ days); and regulation of fluxes to groundwater using an export term ( $\left.\mathrm{x}_{2} \mathrm{~mm}\right)$. GR4JSG adds snow and ice stores that are filled with precipitation when the temperature (combined according to $\mathrm{T}_{\text {fraction }}$ ratio of min and max) is below a threshold $\mathrm{T}_{\text {accumThreshold }}\left({ }^{\circ} \mathrm{C}\right)$ and melts according to a degree day factor for snow $\left(\mathrm{DDF}_{\text {snow }} \mathrm{mm} /{ }^{\circ} \mathrm{C}\right)$ and for glaciers $\left(\mathrm{DDF}_{\text {ice }} \mathrm{mm} /{ }^{\circ} \mathrm{C}\right)$ when above a threshold $\mathrm{T}_{\text {melt }}\left({ }^{\circ} \mathrm{C}\right)$.

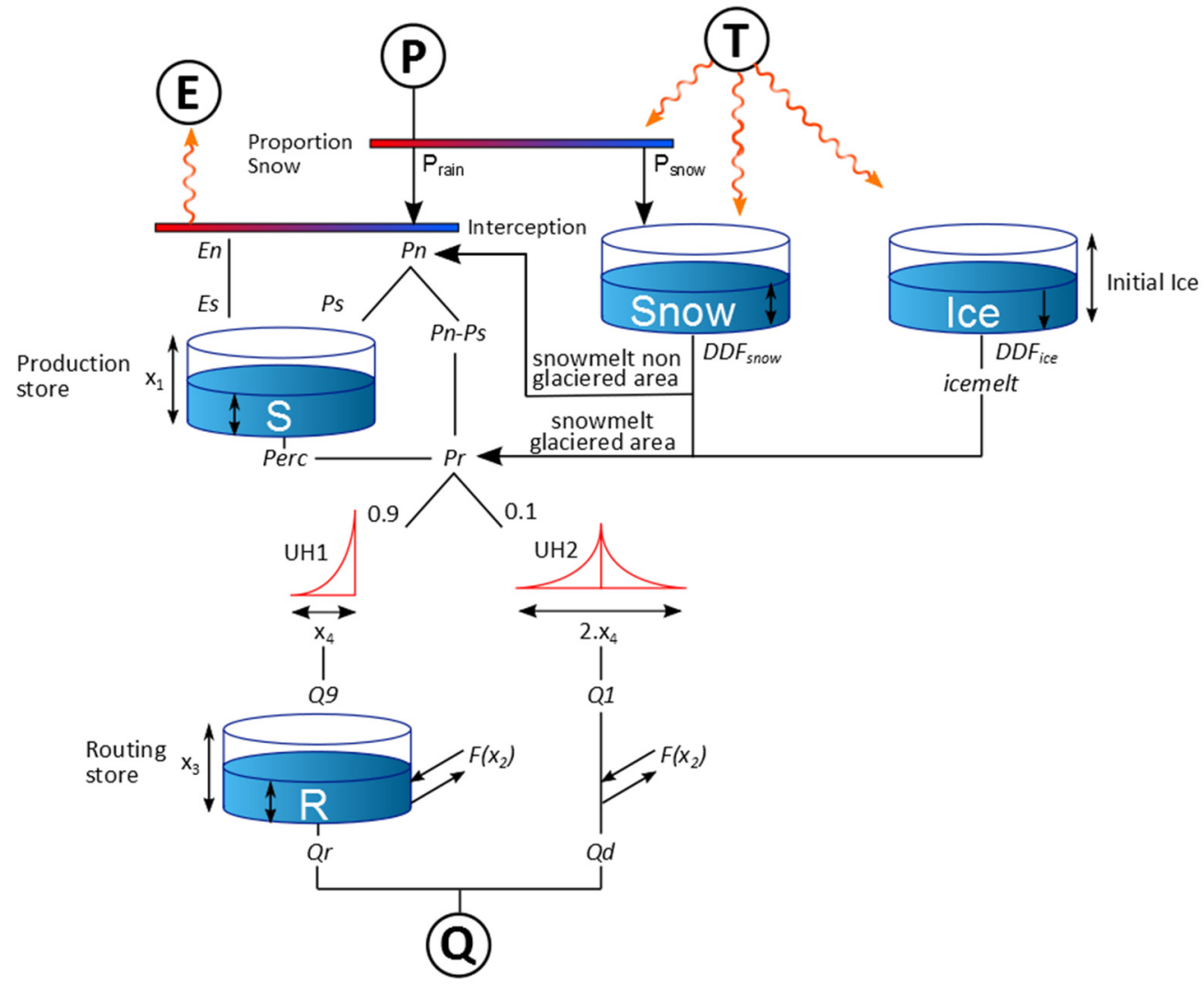

Figure 2. The conceptual processes of the GR4JSG model (Nepal et al, 2017).

The forcing data for the model is daily rainfall, temperature (minimum and maximum) and potential evapotranspiration, and the model requires snow extent and stream-flow data for calibration. In total there are five parameters that control the snow and glacial processes $\left(\mathrm{T}_{\text {fraction, }}, \mathrm{T}_{\text {accumThreshold, }} \mathrm{T}_{\text {melt }}, \mathrm{DDF}_{\text {ice }}\right.$ and $\left.\mathrm{DDF}_{\text {snow }}\right)$, and four parameters that control the runoff processes for GR4JSG ( $\mathrm{x}_{1}, \mathrm{x}_{2}, \mathrm{x}_{3}$ and $\left.\mathrm{x}_{4}\right)$. We applied the GR4JSG model to 82 sub-catchments of the Koshi (up to Nepal considering Chatara discharge station as an outlet) with a separate functional unit for every combination of elevation band and glaciated areas as shown in Table 1.

Table 1. The functional units represent altitude bands and areas of Non-Glacier (NG) and Glacier(GL)

\begin{tabular}{|lrr}
$\begin{array}{l}\text { Functional } \\
\text { Unit }\end{array}$ & \multicolumn{1}{c}{$\begin{array}{l}\text { Lower } \\
\text { (mASL) }\end{array}$} & \multicolumn{2}{c|}{$\begin{array}{l}\text { Upper } \\
\text { (mASL) }\end{array}$} \\
\hline NG1 & 0 & 600 \\
\hline NG2 & 601 & 800 \\
NG3 & 801 & 1000 \\
\hline NG4 & 1001 & 1200 \\
\hline NG5 & 1201 & 1400 \\
\hline NG6 & 1401 & 1600 \\
\hline NG7 & 1601 & 1800 \\
\hline NG8 & 1801 & 2000 \\
\hline NG9 & 2001 & 2200 \\
\hline NG10 & 2201 & 2400 \\
\hline NG11 & 2401 & 2600 \\
\hline NG12 & 2601 & 2800 \\
\hline NG13 & 2801 & 3000 \\
\hline NG14 & 3001 & 3200 \\
\hline NG15 & 3201 & 3400 \\
\hline NG16 & 3401 & 3600 \\
\hline
\end{tabular}

\begin{tabular}{|lrr|}
\hline $\begin{array}{l}\text { Functional } \\
\text { Unit }\end{array}$ & \multicolumn{1}{c}{$\begin{array}{l}\text { Uower } \\
\text { (mASL) }\end{array}$} & $\begin{array}{l}\text { Upper } \\
\text { (mASL) }\end{array}$ \\
\hline NG17 & 3601 & 3800 \\
\hline NG18 & 3801 & 4000 \\
\hline NG19 & 4001 & 4200 \\
\hline NG20 & 4201 & 4400 \\
\hline NG21 & 4401 & 4600 \\
\hline NG22 & 4601 & 4800 \\
\hline NG23 & 4801 & 5000 \\
\hline NG24 & 5001 & 5200 \\
\hline NG25 & 5201 & 5400 \\
\hline NG26 & 5401 & 5600 \\
\hline NG27 & 5601 & 5800 \\
\hline NG28 & 5801 & 6000 \\
\hline NG29 & 6001 & 6500 \\
\hline NG30 & 6501 & 7000 \\
\hline NG31 & 7001 & 9000 \\
\hline
\end{tabular}

\begin{tabular}{lrr}
\hline $\begin{array}{l}\text { Functional } \\
\text { Unit }\end{array}$ & \multicolumn{2}{c}{$\begin{array}{l}\text { Lower } \\
\text { (mASL) }\end{array}$} \\
\hline GL17 & 3601 & 3800 \\
GL18 & 3801 & 4000 \\
GL19 & 4001 & 4200 \\
\hline GL20 & 4201 & 4400 \\
\hline GL21 & 4401 & 4600 \\
GL22 & 4601 & 4800 \\
GL23 & 4801 & 5000 \\
GL24 & 5001 & 5200 \\
GL25 & 5201 & 5400 \\
\hline GL26 & 5401 & 5600 \\
\hline GL27 & 5601 & 5800 \\
\hline GL28 & 5801 & 6000 \\
GL29 & 6001 & 6500 \\
\hline GL30 & 6501 & 7000 \\
\hline GL31 & 7001 & 9000 \\
\hline
\end{tabular}


We generated the model's input rainfall by spatially averaging a gridded dataset across sub-catchment areas. The ESDIIM (Song et al, 2013) method was used to interpolate station data with account to precipitation gradients related to elevation, longitude and latitude at $2.5 \mathrm{~km}^{2}$ for areas below $3000 \mathrm{mASL}$. Cross validation of the $2.5 \mathrm{~km}^{2}$ dataset against held back station data showed an average error of around $20 \%$. We combined the $2.5 \mathrm{~km}^{2}$ gridded dataset with a $0.5^{\circ}$ WATCH reanalysis data (Weedon et al, 2014) for areas above $3000 \mathrm{mASL}$ because the $2.5 \mathrm{~km}^{2}$ gridded dataset predicted precipitation at higher elevations that was too high. Based on available data, we combined two gridded temperature inputs: for Nepal, we used the ANUCLIM tool (McMahon et al, 1995) to generate a $1 \mathrm{~km}^{2}$ gridded monthly values that we then disaggregating to daily; and for China we used a $0.5^{\circ}$ daily WATCH reanalysis dataset. The model's potential evaporation was calculated using Penman-Monteith equation for Nepal (at Taplejung station, with exponential decay to account for elevation lapse rate) and spatially averaged $0.5^{\circ} \mathrm{WATCH}$ reanalysis for China.

We parameterised the model in three steps: the first step was calibration of snow parameters, the second step was derivation of glacial parameter $\left(\mathrm{DDF}_{\text {ice }}\right)$ and the third step was the calibration of flow parameters. For snow parameters, we used the Shuffled Complex Evolution (Duan et al, 1993) algorithm to select a set of snow parameters that produced snow extents that best matched cloud-filtered remotely-sensed snow extents for five catchments according to Nash-Sutcliffe efficiency (NSE) objective function calculated daily; and evaluated through leave-one-out-cross validation. The cloud-filtered remotely sensed snow extent product was a daily MODIS snow cover imagery (Hall et al, 1995) that we filtered using a Hidden Markov Model with two states: one for land and one for snow (Chua et al, 2017). To derive the glacial parameter, we chose values for $\mathrm{DDF}_{\text {ice }}$ that forced the change in mass to match the ICE-Sat derived values reported by Kaab et al (2012). Forcing the glacial parameter to a prior value was required because Nepal et al (2017) showed, for a selected catchment (Tamor), that the $\mathrm{DDF}_{\text {ice }}$ parameter was not identifiable from streamflow alone. For calibration of flow parameters, we used the Shuffled Complex Evolution algorithm to select stream-flow parameters for each of the six major catchments. We used daily NSE and Bias as the objective function for evaluating similarity, and split the simulation into separate periods for calibration and validation (the periods varied depending on data availability - see Table 4).

\section{RESULTS}

Based on the calibrated model, the contribution to stream-flow was between $2.6 \%$ (Likhu) and $12.7 \%$ (Tamakoshi) snow melt, and between $0.5 \%$ (Likhu) and 4.7\% (Arun) glacier melt (see selected catchments in Figure 3). The major carriers of water are the Arun and Sun Koshi Rivers. Runoff is being generated predominantly at elevations between $2000 \mathrm{mASL}$ and $4000 \mathrm{mASL}$ - around the same elevation as snow fall is greatest. According to the model, the snow and glaciers are melting at roughly the same time as monsoon rains are falling.

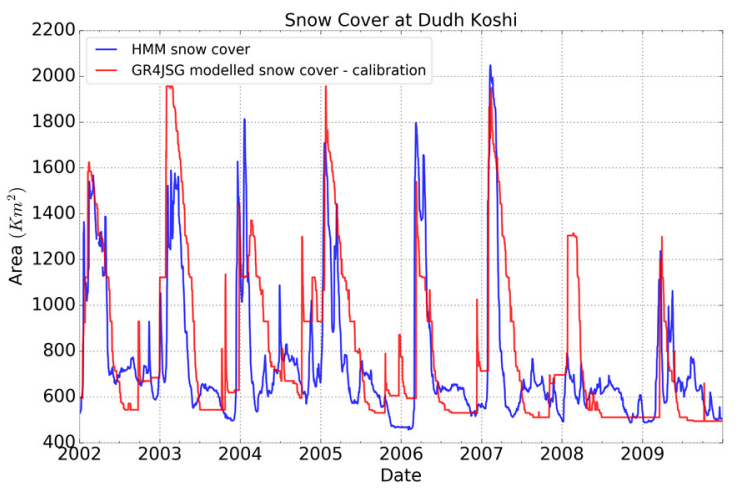

Contributions to runoff in Dudh Koshi

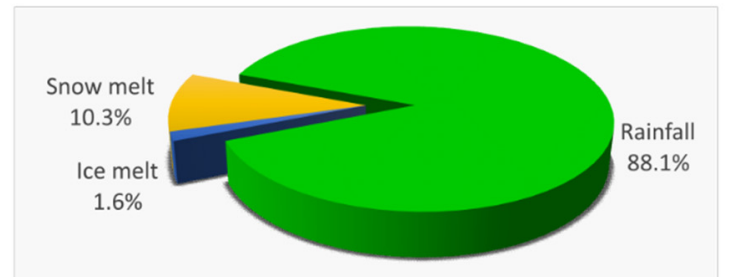

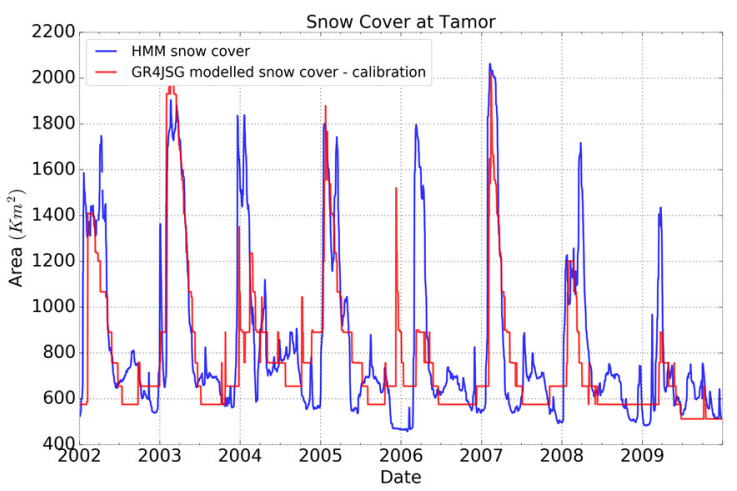

Contributions to runoff in Sun Koshi

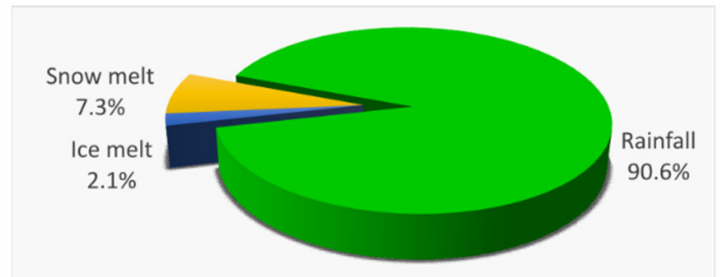

Figure 3. Contribution to runoff from snow melt, ice melt and rainfall for the Dudh Koshi and the total catchment at the Sun Koshi outlet (Penton et al, 2017). Results for other catchments in Penton et al (2017). 
The leave-one-out cross validation of snow extent had an average bias of $20 \%$ and average daily NSE of 0.13 across the five catchments. The patterns of snow accumulation and melting were in line with expectations, though the statistical performance was affected by error estimating snow extent from observed MODIS as well as model errors. We selected the snow parameters (performance shown in Table 2) from the calibration with Likhu excluded (its catchment area was very cloud effected). For the selected parameter set, the $\mathrm{T}_{\text {fraction }}$ value was high (i.e. the daily representative air temperature was calculated as $78 \%$ of $\mathrm{T}_{\max }$ and $22 \%$ of $\mathrm{T}_{\min }$ ), suggesting that temperature inputs might be too cold or the calibration process was compensating for some other factor (individual results in Table 3). The calculated $\mathrm{DDF}_{\text {ice }}$ was very low $\left(0.66 \mathrm{~mm} .{ }^{\circ} \mathrm{C}^{-1}\right.$. day $\left.{ }^{-1}\right)$, either a consequence of the high $\mathrm{T}_{\text {fraction }}$ or an underestimate of glacial melt by Kaab et al (2012).

Table 2. Snowmelt evaluation for five sub-catchments of Eastern Himalayas. Note, Likhu performed badly due to gross misclassification of monsoon cloud as snow (Likhu is more sensitive than other catchments due to its low elevation).

\begin{tabular}{llllllllllll} 
& \multicolumn{2}{l}{ Dudh Koshi } & \multicolumn{2}{l}{ Indrawati } & \multicolumn{2}{l}{ Likhu } & \multicolumn{2}{c}{ Tama Koshi } & \multicolumn{2}{l}{ Tamor } \\
& Bias (\%) & NSE & Bias (\%) & NSE & Bias (\%) & NSE & Bias (\%) & NSE & Bias (\%) & NSE \\
\hline $\begin{array}{l}\text { Regional } \\
\text { Performance }\end{array}$ & 7.70 & 0.12 & -19.77 & 0.12 & -52.05 & -0.52 & -14.65 & 0.35 & -7.14 & 0.52 \\
\hline
\end{tabular}

The validation of streamflow had mean bias of $10 \%$ and mean NSE of 0.77 across the 8 validation periods (individual results in Table 4). For several catchments (e.g. Dudh Koshi, Likhu and Tama Koshi) the groundwater flux term $\mathrm{x}_{2}$ was unrealistic, near its upperbound of 5, which suggested insufficient melt or precipitation. For many of the catchments, the soil production store $\mathrm{x}_{1}$ was very large, which, we suggest, emerged from the calibration to produce reasonable recessions and release water through evaporation.

Table 3. Calibrated streamflow parameter values. Parameter values on the boundaries of the recommended value ranges are shown in red.

\begin{tabular}{|c|c|c|c|c|c|c|c|c|}
\hline Catchment & $\mathrm{x}_{1}(\mathrm{~mm})$ & $\mathrm{x}_{2}(\mathrm{~mm})$ & $\mathrm{x}_{3}(\mathrm{~mm})$ & $\mathrm{x}_{4}$ (days) & $\begin{array}{l}\mathrm{DDF}_{\text {snow }} / \mathrm{DDF}_{\text {ice }} \\
\left(\mathrm{mm} \cdot{ }^{\circ} \mathrm{C}^{-1} \cdot \mathrm{day}^{-1}\right)\end{array}$ & $\begin{array}{l}\text { TMeltThreshold } \\
\left({ }^{\circ} \mathrm{C}\right)\end{array}$ & $\begin{array}{l}T_{\text {accumThreshold }} \\
\left({ }^{\circ} \mathrm{C}\right)\end{array}$ & $\mathrm{T}_{\text {fraction }}$ \\
\hline Arun & 1240.21 & 1.47 & 56.83 & 1.10 & 3.29 / 0.66 & -0.78 & 2.96 & 0.78 \\
\hline DudhKoshi & 596.34 & 4.87 & 349.02 & 0.59 & 3.29 / 0.66 & -0.78 & 2.96 & 0.78 \\
\hline $\begin{array}{l}\text { Indrawati/ } \\
\text { Melamchi }\end{array}$ & 1777.23 & 0.36 & 360.70 & 0.63 & 3.29 / 0.66 & -0.78 & 2.96 & 0.78 \\
\hline Likhu & 1801.81 & 5.00 & 298.96 & 1.15 & 3.29 / 0.66 & -0.78 & 2.96 & 0.78 \\
\hline TamaKoshi & 423.24 & 4.62 & 498.07 & 1.12 & 3.29 / 0.66 & -0.78 & 2.96 & 0.78 \\
\hline Tamor & 1648.47 & 1.62 & 284.83 & 0.50 & 3.29 / 0.66 & -0.78 & 2.96 & 0.78 \\
\hline SunKoshi & 1845.20 & -2.83 & 208.59 & 1.12 & N/A & N/A & N/A & N/A \\
\hline
\end{tabular}

Table 4. Evaluation of streamflow performance (Penton et al., 2017).

\begin{tabular}{llllllll}
\hline Catchment & & Calibration & & & Validation \\
& Period & Bias (\%) & NSE & Period & Bias (\%) & NSE \\
\hline Arun & $1989-1996$ & -8.4 & 0.64 & $2000-2009$ & -4.5 & 0.70 \\
\hline Dudh Koshi & $1986-1996$ & -5.3 & 0.80 & $2000-2009$ & -11.5 & 0.72 \\
\hline Indrawati / Melamchi & $1986-1996$ & -0.7 & 0.88 & $2000-2009$ & 13.9 & 0.79 \\
\hline Likhu & $1994-2008$ & -5.8 & 0.63 & $1986-1991$ & 9.5 & 0.69 \\
\hline Tamakoshi & $1995-2009$ & -0.7 & 0.77 & $1986-1994$ & -15.8 & 0.82 \\
\hline Tamor & $2001-2004$ & -2.4 & 0.85 & $2005-2009$ & 6.8 & 0.83 \\
\hline Sun Koshi (Chatara) & $1996-2003$ & 9.8 & 0.82 & $2005-2009$ & 15.1 & 0.80 \\
\hline
\end{tabular}




\section{DISCUSSION AND CONCLUSIONS}

We are confident that we have captured the streamflow reasonably at a range of sites across the basin (see Table 4), giving the relative discharges in Figure 4. This can be evaluated by the performance of the model in replicating observed stream-flow data. Other studies report model performance for streamflow with values ranging from NSE 0.58-0.89 for Tamor, NSE 0.63-0.89 for Dudh Koshi and NSE 0.62-0.87 for Koshi at Chatara (details in Penton et al, 2017). Nepal et al (2017) reports performance against snow extent, $\mathrm{R}^{2}$ of 0.46 , for the Tamor catchment. Each study uses different periods for evaluation, and some evaluate NSE monthly, which makes a direct comparison difficult, but the results of this modelling are similar to prior work.

Even with the reasonably complicated methods, and rigorous treatment of input data and consideration of errors, we are not confident with the attribution of fluxes between snow, glacier, precipitation and evaporation. While the calibration to snow extent is necessary to constrain the model to physical reality, the model fit (around 0.12 NSE) is poor. This could be true of other studies that do not report of evaluate snow store properties. Some of the errors stem from the coarse gridded datasets used for the data-poor regions (hence better results in Nepal et al, 2015 and Nepal et al, 2017), and others from details of the conceptualisation (e.g. refreeze as in Lutz et al. 2014, avalanche, reflecting effects of aspect Penton et al, 2015).

What this means is that model predictions will be different depending on the assumptions around glacier decay rates, temperature projections, etc. In particular, model predictions of base-flows at the end of the dry season will vary depending on these assumptions. From a decision-making perspective, the future flows at the end of the dry season are important because they determine the hydropower generated (generators need to guarantee dry season supply), the concentrations of sediment and the amount of water available for canal systems in Nepal and India that are fed from the Koshi Barrage at the end of the system.

We would suggest further research to test and constrain the model to observations would reduce the inherent uncertainty of the model and improve the defensibility of predictions. Options for improving observations include incorporating remotely sensed rainfall products (or any other high resolution products), tracer studies of stream-flow origin (assuming different signatures from glaciers) and more advanced snow-cover products.

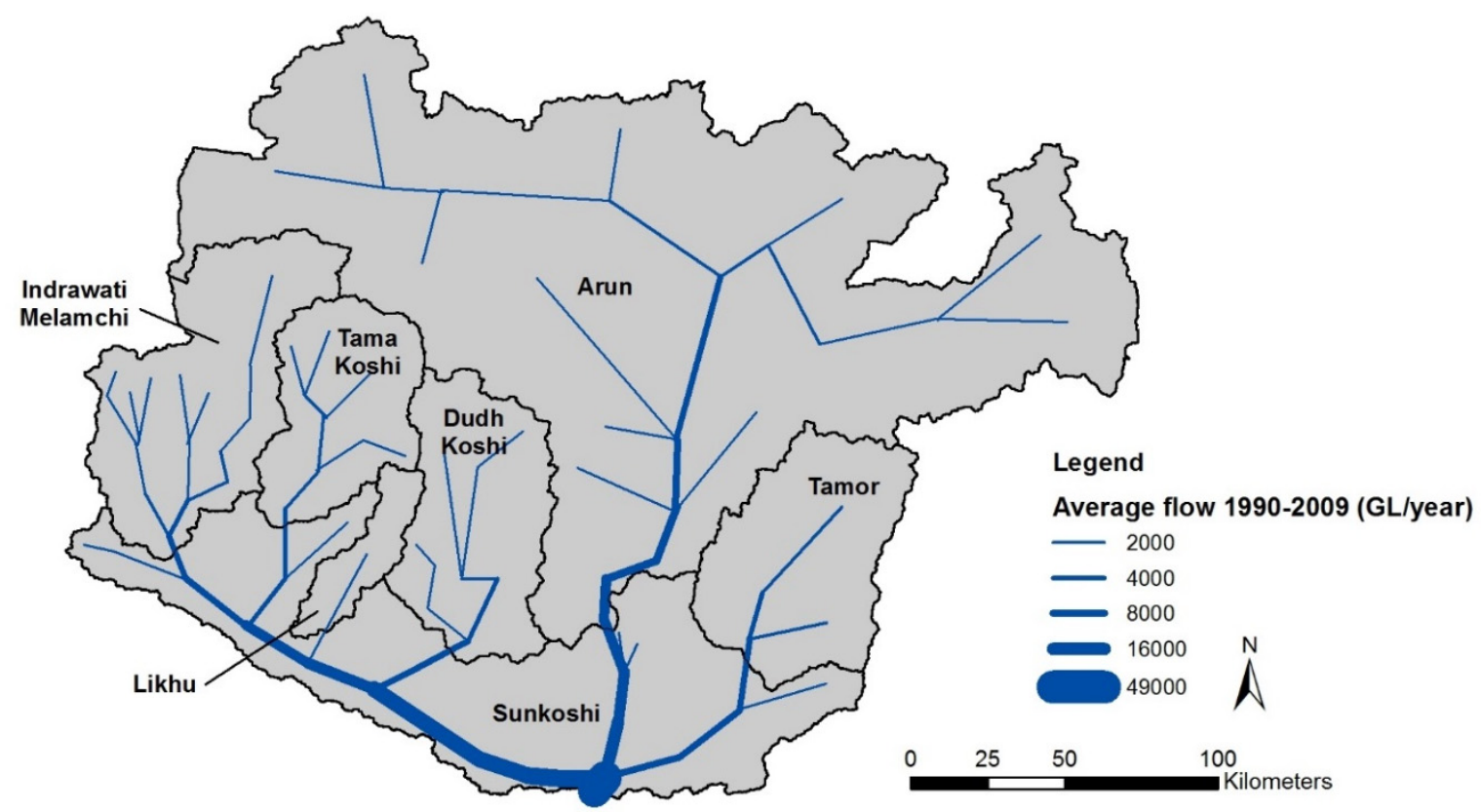

Figure 4. Average streamflow in the Nepal Koshi Basin (Penton et al., 2017). 


\section{ACKNOWLEDGMENTS}

The Department of Foreign Affairs and Trade (DFAT) through the South-Asia Development Programme funded this work in CSIRO.

We acknowledge the assistance of the Department of Hydrology and Meteorology (DHM) and thank the Government of Nepal for allowing us access to hydro-climate data. We thank the many individuals at ICIMOD and CSIRO that assisted, including reviewing of manuscripts.

This report provides a synthesis of material which is also described Penton et al (2017)'s CSIRO report.

\section{REFERENCES}

Bharati L, Gurung P, Jayakody P (2012). Hydrologic characterization of the Koshi Basin and the impact of climate change, Hydro Nepal: Journal of Water, Energy and Environment, 11(1), 18-22.

Chua S, Penton DJ, Van Dijk A (2017). Interpreting transition and emission probabilities from a Hidden Markov Model of remotely sensed snow cover in a Himalayan Basin. Submitted to MODSIM2017, 25th International Congress on Modelling and Simulation. Modelling and Simulation Society of Australia and New Zealand, December 2017.

Doody, T. M., Cuddy, S. M., \& Bhatta, L. D. (2016). Connecting flow and ecology in Nepal: current state of knowledge for the Koshi Basin. Sustainable Development Investment Portfolio (SDIP) project. CSIRO, Australia.

Duan, Q. Y., Gupta, V. K., \& Sorooshian, S. (1993). Shuffled complex evolution approach for effective and efficient global minimization. Journal of Optimization Theory and Applications, 76(3), 501-521.

Hall DK, Riggs GA, Salomonson VV (1995). Development of methods for mapping global snow cover using moderate resolution imaging spectroradiometer data, Remote Sensing of Environment, 54(2), 127-140.

Kaab A, Berthier E, Nuth C, Gardelle J, Arnaud Y (2012). Contrasting patterns of early twenty-first-century glacier mass change in the Himalayas, Nature, 488(7412), 495-498.

Lutz AF, Immerzeel WW, Shrestha AB, Bierkens MFP (2014). Consistent increase in High Asia's runoff due to increasing glacier melt and precipitation, Nature Clim. Change, 4(7), 587-592.

McMahon, J. P., Hutchinson, M. F., Nix, H. A., \& Ord, K. D. (1995). ANUCLIM user's guide. Centre for Resource and Environmental Studies, Australian National University, Canberra.

MFD (2016). Government of Nepal, Meteorological Forecasting Division, accessed 21/6/2016 $<$ http://www.mfd.gov.np/city?id=31>

Nepal, S., Zheng, H., Penton, D. J., \& Neumann, L. E. (2015). Comparative performance of GR4JSG and J2000 hydrological models in the Dudh Koshi catchment of the Himalayan region. MODSIM2015. MSSANZ, 2395-2401.

Nepal, S., Chen, J., Penton, D. J., Neumann, L. E., Zheng, H., \& Wahid, S. (2017). Spatial GR4J conceptualization of the Tamor glaciated alpine catchment in Eastern Nepal: evaluation of GR4JSG against streamflow and MODIS snow extent. Hydrological Processes, 31(1), 51-68.

Panday PK, Williams CA, Frey KE, Brown ME (2014). Application and evaluation of a snowmelt runoff model in the Tamor River basin, Eastern Himalaya using a Markov Chain Monte Carlo (MCMC) data assimilation approach. Hydrological Processes 28(21), 5337-53.

Penton, D. J., Neumann, L. E., Karki, R., \& Nepal, S. (2015). Verifying Temperature Lapse Rates in the Eastern Himalayas using Landsat 7 and 8. MODSIM2015. MSSANZ, 2395-2401.

Penton, D. J., Neumann, L. E., Doody, T. M., Foran T, Grigg N. J., Zheng H., Cuddy S. M., Dolk M. M., Siddiqui S., Stratford D., Boudier E., Chua S. T. and Fleming D. A. (2016). Preliminary analysis of hydroclimate and streamflow modelling in the Koshi Basin: Climate, hydrology, ecology and institutional setting. Sustainable Development Investment Portfolio (SDIP) project. CSIRO, Australia.

Perrin C, Michael C, Andreassian V (2003). Improvement of a parsimonious model for streamflow simulations. Journal of Hydrology, 279, 275-289.

Song, Y., Wang, Q.J., Robertson, D.E., Mashford, J. (2013). Estimating sub-catchment rainfall from rain gauge observations at daily time steps, CSIRO Water for a Healthy Country Flagship, Melbourne. 